\title{
REFLECTIONS
}

\section{Virtual Care: Choosing the Right Tool, at the Right Time}

Kumara Raja Sundar, MD

Kaiser Permanente of Washington, Burien, Washington
Conflicts of interest: author reports none.

\section{CORRESPONDING AUTHOR}

Kumara Raja Sundar

Kaiser Permanente of Washington 140 SW 146th St

Burien, WA 98166

raja.sundar825@gmail.com

\begin{abstract}
When the immediate threat of COVID-19 subsides, the future of health care will involve more virtual care. Before the pandemic, patient choice rather than clinician guidance determined which medium (telephone visits, video visits, electronic messaging) was used to receive care. Two media synchronicity theory principles-conveyance and convergence-can create a framework for determining how to choose the right medium of care for the patient. The author describes how it changed their practice and decision making with a patient story that required the use of multiple virtual care options.
\end{abstract}

Ann Fam Med 2021;19:365-367. https://doi.org/10.1370/afm.2693.

T my integrated health system, patients can connect with clinicians through multiple virtual care options. In my mind, however, these options were all complementary to the traditional office visit. Until recently, I believed the office visit was irreplaceable in its ability to clarify symptoms, obtain information, and devise a treatment plan. Whenever there was resistance or doubt, I recommended an office visit, generously and eagerly, until the genesis of a global pandemic necessitated a change in my approach.

Due to COVID-19, our health system shifted to a "Virtual First" model. Patients could no longer make an office visit unless a clinician approved it. Instead of office visits, my day was now comprised of billable telephone visits, video visits, asynchronous messaging, and synchronous messaging. In our system, asynchronous messaging occurs through the electronic medical record (EMR) portal where an immediate response is not required, like e-mail. Synchronous messaging occurs through a platform where an immediate response is needed, like instant messaging. My days in a primary care clinic looked different now.

Although I accepted this new model of care, given the pandemic's changing demands, I soon learned that I did not know how to choose one care medium over another. I could not find guidance in the medical literature, either. Knowing I had to be intentional in which method I recommended, I set out to see if I could find answers.

\section{THE WRONG METHOD OF COMMUNICATION}

After a telephone visit one day, the importance of choosing the right method of communication became clear. The mother of a 4 -year-old scheduled a telephone visit with me to review a cough her child had had for 3 weeks. On chart review, I read that the patient's mother had already participated in 2 telephone visits in the last few weeks with different clinicians. Both times, they consoled her, saying that it was a viral upper respiratory infection, probably not COVID-19. They advised her to watch for worsening symptoms and follow-up as necessary. She called back because she was worried about her child's shortness of breath. 
She began our call concerned. "I'm worried the cough isn't getting better. Well, the cough got better for 5 days, but now it's back. I also think he is short of breath right now."

After a few weeks of primarily providing virtual care, I realized that shortness of breath is as elusive of a symptom to characterize as dizziness. I attempted to clarify, "When you mean short of breath, are you saying he appears to be suffocating, gasping for breathlike after running fast? Or having a lot of congestion, feeling tired, or needing to take an extra deep breath occasionally?"

She paused, "I think just taking an extra deep breath, occasionally."

"Okay. That's good. That is encouraging because it doesn't sound like he is struggling to breathe and whatever is going on isn't harming him right now." I continued to substitute my physical exam by asking for the mother's observations. "Have you noticed retractions?"

"What are those?"

"Oh, sorry, let me explain. When you see the chest wall muscles straining to help a child breathe, it's called retractions. For example, when they're breathing hard, their belly pulls in beneath their rib cage."

"Oh, okay. No, I don't think so. I haven't noticed." She then pleaded, "Can he just be seen in-person? I just wish this would all be over so you can see him and let me know if everything is okay." Her tone told me that she had given up on the idea of communicating through the telephone. I was ready to do the same. I missed the office visit. I continued to reassure her about her child's illness and attempted to quell her fears, but we both ended up dissatisfied with the encounter.

At the end of the visit, she wanted to know if she should follow up by telephone, video, or secure messaging. I didn't have a confident answer. How should I decide the best type of visit for the patient? Do I rely on my current assessment about the child's illness and advise the mother to send me a message through the EMR to check-in? Or do I yield to the mother's request and my uncertainty to give them one of the limited, coveted office visits in the clinic?

I didn't know how to determine which communication method would best help the patient resolve their problem. I could not find medical literature addressing how, why, or when to choose specific methods. As I reflected on the telephone visit, I realized that the nature of the telephone visit impeded effective communication. I had difficulty communicating signs of acute illness requiring more urgent care through the telephone in an easy, effective way that she understood. Without nonverbal cues, I didn't grasp the mother's frustration until the end of our conversation and could not convey my reassurance with just the tone of my voice. We had a complication with communication.

\section{MATCHING COMMUNICATION PROCESS TO MEDIA}

Outside of health care, researchers have studied methods of communication in organizations and their effectiveness. They have found effective communication occurs when communication processes are well matched with media capability. They describe 2 types of processes: conveyance and convergence. Conveyance processes focus on transmitting and processing diverse information to understand the situation. It is a process that requires time to analyze data, create patterns, and make conclusions. In contrast, convergence processes focus on discussing pre-processed information to achieve a mutual understanding. It often requires a rapid exchange of information to allow immediate feedback to test and verify each other's knowledge. ${ }^{1}$

For communication to be effective, conveyance needs a medium with 2 characteristics: (1) ability to read and reexamine the message during or after the discussion, and (2) ability to rehearse and edit the message before sending it. Essentially, such media allow greater time to process new information. On the other hand, convergence processes require a medium with 2 different characteristics: (1) ability to deliver the message and communicate in real-time and, (2) ability to express the message in multiple ways-visual, physical, written, and verbal.

In health care, an example of matching conveyance to the right medium is creating a complicated treatment plan and printing an after-visit summary. Patients have poor recall with recommendation plans, especially if it involves multiple diagnostic studies, medication prescriptions, and follow-up steps. ${ }^{2} \mathrm{With}$ a printed after-visit summary, I can use previously created phrases that avoid medical jargon and are written in a fifth- to sixth-grade reading level. This medium also enables the patient to review it at home multiple times to understand our plan better. In contrast, using a medium like a telephone visit without accompanying media to explain a plan means that I rely on myself to vocalize messages accurately and my patient's memory to remember it. Relying on memory can place a more significant cognitive load on both of us and lead to erroneous action. ${ }^{3,4}$

An example of matching convergence to the right medium is managing chronic pain in a video or office visit. Managing chronic pain requires understanding patient's values and emotions and creating shared goals of care, especially if they're on chronic opioid therapy. 
With a video visit or office visit, I can rely judiciously on nonverbal gestures like eye contact, facial expressions, and body postures to promote trust and rapport. By communicating in real time, I can also ensure that we achieve a mutual understanding of our goals. Conversely, when I have sent a message through the EMR about a patient's pain medication, I have received angry replies stating that I do not understand their situation nor care about them. Using the wrong medium, like a secure message, in a convergence process like this can increase delays in understanding and sometimes actively promote misunderstanding. ${ }^{1}$

Neither conveyance nor convergence processes occur in isolation. Without conveyance, the result will be incorrect conclusions, and without convergence, the result will be a lack of mutual understanding about the way forward. Initially, after the phone visit described above, I was struggling to answer the question, "What is the best care medium to serve this patient?" But there is no "best" medium. I was asking the wrong question-I should be asking, "Which care medium is right for this patient and in what order?"

\section{PUTTING THEORY INTO ACTION}

Soon after I learned this theory, I applied it in my practice. A 55-year-old gentleman presented with intermittent cough on our synchronous (instant) messaging service. He had symptoms typical of an upper respiratory infection and wanted to make sure he didn't have COVID-19. It appeared to be more of a convergence process than a conveyance process-we needed to communicate in real time to answer his questions and assuage his fears. Synchronous messaging seemed appropriate. If he had significant anxiety, a medium like a video visit or telephone visit - where I can show empathy with physical gestures or vocal tone-would be more appropriate. Through messaging, I reassured the patient and concluded that he didn't meet the testing criteria for COVID-19 right now.

A week later, he returned to our synchronous messaging service with fevers and chills. A COVID-19 test was ordered, which returned negative. A few days after the negative result, he sent me an asynchronous message through the EMR concerned about his continued intermittent chills. It was getting more complicated. My instinct was to do an office visit, so I could obtain all the information, do an exam, and create a plan of care in a controlled setting. ${ }^{1}$

But then I remembered what I had learned about communication theory and realized that I needed more conveyance, not convergence before figuring out what to do next. I needed time to process all the information and determine next steps. Given he had explained his symptoms multiple times already, I could do this over asynchronous messaging. I compiled what I understood about the patient from reviewing his electronic messages and replied to him. He gave me a timeline of his symptoms, including images of a recent rash that he had developed. Asynchronous messaging seemed to be the right medium and allowed me to process a complicated history with multiple symptoms and think deeply to create a plan of care for him.

Eventually, I diagnosed him with secondary syphilis. We made a telephone visit to discuss the diagnosis, and I sent him a message with an attachment about secondary syphilis and the treatment plan. His journey in our system with his illness included synchronous messaging, asynchronous messaging, and telephone visits. Although the decision about which care medium to use-and in what order-still required clinical judgment, I felt like I had a rational basis for choosing one medium over another.

\section{USING ALL OUR TOOLS}

Patients benefit from telehealth's convenience when they have access to the right technology, but the healing journey for patients requires all care options, including office visits when necessary. Sometimes, it is only in a face-to-face office visit with a bedside exam that we can convincingly communicate, "It'll be okay. We will face this together." Given the rapid proliferation of telehealth, though, primary care must redefine what it means to provide first-contact, comprehensive, continuous, coordinated care. We must guide patients toward the right care medium for them and in the correct order and use all our tools efficiently and effectively. In this new era of telehealth, it is the only way we will be able to achieve our mission of healing.

To read or post commentaries in response to this article, go to https://www.AnnFamMed.org/content/19/4/365/tab-e-letters.

Key words: telemedicine; judgement; office visits; primary health care

Submitted May 4, 2020; submitted, revised, August 21, 2020; accepted September 1, 2020.

\section{References}

1. Dennis AR, Fuller RM, Valacich JS. Media, tasks, and communication processes: a theory of media synchronicity. Manage Inf Syst Q. 2008;32(3):575-600.

2. Laws MB, Lee $Y$, Taubin T, Rogers WH, Wilson IB. Factors associated with patient recall of key information in ambulatory specialty care visits: results of an innovative methodology. PLoS One. 2018;13(2): e0191940.

3. Te'eni D. A cognitive-affective model of organizational communication for designing IT. Manage Inf Syst Q. 2001;25(2):251-312.

4. Weick KE, Meader DK. Sensemaking and group support systems. In: Jessup L, Valacich J, eds. Group Support Systems: New Perspectives. MacMillan; 1993:230-52. 